Applied nutritional investigation

\title{
Effect of television viewing on food and nutrient intake among adolescents
}

\author{
Elisabete Ramos Ph.D. ${ }^{\text {a,b,c,* }}$, Andreia Costa M.P.H. ${ }^{a}$, Joana Araújo M.P.H. ${ }^{\text {a,b,c }}$, Milton Severo Ph.D. ${ }^{\text {a, b,c }}$, \\ Carla Lopes Ph.D. ${ }^{\text {a,b,c }}$
}

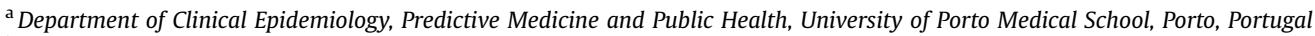

${ }^{\mathrm{b}}$ Cardiovascular Research and Development Unit, University of Porto Medical School, Porto, Portugal

${ }^{\mathrm{c}}$ Institute of Public Health, University of Porto, Porto, Portugal

\section{A R T I C L E I N F O}

\section{Article history:}

Received 23 October 2012

Accepted 14 May 2013

\section{Keywords:}

Adolescent

Dietary intake

Energy intake

Nutrients

Television

\begin{abstract}
A B S T R A C T
Objective: Among the behaviors associated with food intake, exposure to television is particularly important given the number of adolescents exposed. Also, increased time spent watching television has been associated with physical inactivity and with less desirable dietary intake among adolescents. The aim of this study was to examine the association between television viewing and dietary intake among 13-y-old adolescents.

Methods: A cross-sectional evaluation was carried out in the 2003-2004 school year, including adolescents born in 1990 and enrolled in the schools of Porto, Portugal. Time spent watching TV was collected by self-administered questionnaires and dietary intake was evaluated using a food frequency questionnaire. Included in the analysis were 1436 adolescents.

Results: Spending more than 120 min per day watching TV was significantly associated with higher intake of total fat and polyunsaturated fat and with lower intake of magnesium, in both sexes. Additionally, in girls, spending more than 120 min per day watching TV was associated with lower intake of complex carbohydrates, fiber, total vitamin A, folate, vitamin C, calcium, iron, phosphorus, and potassium. In boys, higher intake of saturated fat and cholesterol was found among those spending more time watching TV.

Conclusions: We found that television viewing is associated with higher consumption of foods containing more fats and sugars and a lower consumption of fruits and vegetables. Consequently, adolescents who watched more television had a higher intake of total fat and polyunsaturated fat and a lower intake of minerals and vitamins. This dietary behavior among adolescents may have long-term health implications, not only limited to obesity.
\end{abstract}

(c) 2013 Elsevier Inc. All rights reserved.
Overweight in children and adolescents is increasing on a global scale [1,2] as result of an energy imbalance in which energy intake is greater than energy expenditure. Among the large number of determinants of obesity, time spent watching TV has been recognized as a risk factor for obesity among children and adolescents [3-5]. Furthermore, TV viewing during childhood and adolescence is associated with overweight in adulthood $[6,7]$.

Some mechanisms have been proposed in attempt to explain how TV affects weight gain. One discussed mechanism is the reduction of energy expenditure, both because it is a sedentary activity but also due to the reduction of time spent participating in more active physical activities [8]. Another mechanism is the effect on dietary intake [8]. Previous studies demonstrate that TV

\footnotetext{
* Corresponding author. Tel.: +351225 513 652; fax: +351 225513653 .

E-mail address: eliramos@med.up.pt (E. Ramos).
}

viewing is associated with less desirable dietary behaviors, including increased energy intake [9-12], increased consumption of high-energy foods like snacks, fast-foods, and soft drinks [12-20], and decreased consumption of fruit and vegetables [12,13,16-19,21]. Although this association has been widely studied among children and older adolescents, data from young adolescents are less available.

Transition from childhood to adulthood is called the adolescent period, a time of rapid physical, emotional, and psychological changes, accompanied by biological development characterized by evolving growth and maturation. The definition of the age range of adolescence is variable, but the World Health Organization (WHO) defined it as the period between 10 and $19 \mathrm{y}$ old [22]. During young adolescence, children have progressively more control over what, when, and where they eat, making personal choices and preferences gain priority over eating habits acquired in the family $[23,24]$. They are also more prone to be 
influenced by their peers, other community members, and advertisements [25]. On the other hand, as the majority of previous studies have addressed the relation between TV viewing and obesity, they have focused their analysis on energy or macronutrient intake. To our knowledge, few studies have examined the association between television viewing and the intake of some vitamins and minerals. Thus, the association between television viewing and nutrient intake among young adolescents is still an important issue, particularly because in this period of life the rapid growth creates an increased demand for some nutrients and an inadequate intake during this period can have long-term health implications [26,27].

Among the behaviors that were described as associated with food intake, exposure to television is particularly important given the number of adolescents exposed. Accordingly, the American Academy of Pediatrics recommends that television viewing for children should be limited to no more than $2 \mathrm{~h}$ of quality programming per day [28]. However, results of the 20052006 Health Behaviour in School-aged Children (HBSC) project indicate that $70 \%$ of 13 -y-old adolescents reported watching TV more than $2 \mathrm{~h}$ each day in WHO European regions [29]. In Portugal, $82 \%$ of girls and $76 \%$ of boys reported watching TV more than $2 \mathrm{~h} / \mathrm{d}$ [29].

The aim of this study was to analyze food and nutrient intake according to time spent watching TV, in young adolescents.

\section{Methods}

Participants

A cohort of urban adolescents born in 1990 and enrolled on Porto schools, known by the acronym EPITeen (Epidemiological Investigation of Teenagers' Health in Porto) [30] was evaluated in 2003-2004. We identified 2787 eligible adolescents. Forty-four adolescents (1.6\%) could not be reached (absent from classes during the study period), 583 (20.9\%) were considered refusals because signed informed consent forms were not returned, and 2160 (1561 public and 509 private school students) agreed to participate and provided information at least for part of the planned assessment. This resulted in a $77.5 \%$ overall participation proportion, similar in public and private schools (respectively, 77.7\% versus $77 \%, P=0.709$ ). In Portugal, education is compulsory by law for $13-y$-old adolescents, making schools an ideal sampling setting for achieving representativeness.

The Ethical Committee of the University Hospital of São João, Porto, approved the study. Parents and adolescents received written and oral information explaining the purpose and the design of the study. Written informed consent was obtained from both adolescents and their legal guardians.

\section{Data collection}

The evaluation comprised two self-administered questionnaires (one completed at home, another at school), and a physical examination performed at school.

The home questionnaire was completed by the adolescents, at home, with help from their parents, and inquired into demographic, social, behavioral, and clinical characteristics of the adolescent and family. At school, during the research team's visit, adolescents responded to an additional questionnaire comprising further information on physical activity, smoking, and alcoholic beverage intake.

As part of the home questionnaire, the amount of time spent watching television (including videos and DVDs but not video games or the computer) was evaluated using an open question, separately for weekdays and weekend days. The total time per week and the average daily time were computed and participants were classified into three categories: watching $\leq 60 \mathrm{~min} / \mathrm{d}, 61$ to $120 \mathrm{~min} /$ d, or $>120 \mathrm{~min} / \mathrm{d}$.

As part of the home questionnaire, dietary intake was evaluated using a food frequency questionnaire (FFQ), previously validated in the Portuguese adult population $[31,32]$ according to dietary data available for our country, namely the Portuguese food balance sheets and other specific studies [33,34]. The FFQ was then adapted for adolescents, including foods more frequently eaten by this age group [35], and the adolescents' version comprised 91 food items or beverage categories and a frequency section with nine possible responses ranging from never to six or more times per day. It also included an open-ended section for foods not listed in the questionnaire, but eaten at least once per week. For each food item, participants were asked to indicate their usual consumption over the prior 12 mo. No specific questions on portion size were included on the FFQ. So to estimate the intake in grams or milliliters a standard portion size, estimated from the four 7-d food records used to validate the FFQ and also based on other studies in adolescents [35] has been considered. Food consumption was converted into nutrients using a U.S. database (software Food Processor Plus version 7.02, ESHA Research, Salem, OR, USA), adapted to Portuguese foods and dishes.

Anthropometric measures were obtained with the participant wearing lightweight clothes and no shoes. Weight was measured, in kilograms, to the nearest tenth, using a digital scale (Tanita TBF-300, Tanita Corporation of America, Inc., Illinois, USA), and height was measured, in centimeters, to the nearest tenth, using a portable stadiometer. Body mass index (BMI) was calculated and classified according to the age- and sex-specific BMI reference percentiles, developed by the U.S. Centers for Disease Control and Prevention [36].

\section{Participants}

Of the 2160 participants, 270 did not respond to the home questionnaire, 275 did not answer the FFQ 63 had no information on time spent watching TV, and 23 presented inconsistent information (values extremely high that were identified as outliers when the boxplot of the variable was performed). An additional 93 participants were not considered for this analysis because their total energy intake was more than three times the interquartile range or their intake of fruit or vegetables was more than 1.5 times the interquartile range. Thus our data comprise 1436 adolescents.

\section{Statistical analyses}

Data were analyzed separately for boys and girls. Proportions were compared using the $\chi^{2}$ test and medians using Anova or Kruskal-Wallis test. A $P$-value $<0.05$ was considered statistically significant. Adjustments for parent's education and total energy intake were performed using ordinal logistic regression analysis to estimated proportional odds ratio (POR) and 95\% confidence interval (CI). For the ordinal logistic regression categories of cakes, cookies, soft drinks, chocolates, snacks of chocolate, sweets, fruit, and vegetables were based on quartiles. Pizza, hamburger and salty snacks has lower variability on the frequency of intake reported, thus for these items the analysis was based on tertiles.

\section{Results}

Adolescents included in this analysis were compared with those excluded. Those excluded had a significantly higher proportion of boys, had less educated parents, and were mostly from public schools. No significant differences were found for BMI and for practicing sports to the point of being breathless.

In these 13-y-old Portuguese adolescents, the median (25th75th percentiles) time spent watching television was $120 \mathrm{~min}$ (77.1-180 min). In both sexes, the proportion of adolescents watching more than $120 \mathrm{~min} / \mathrm{d}$ of TV was significantly higher in public schools, compared with the private ones; and the median level of parents' education was lower in adolescents spending more time watching TV. No statistically significant differences were found according to BMI. Girls who spend more than $120 \mathrm{~min} /$ $\mathrm{d}$ watching TV reported to practice sports less frequently (Table 1).

Considering the association between time spent watching TV and food intake, comparing those who watched no more than 60 min of TV, we can state that girls, spending more than $120 \mathrm{~min} / \mathrm{d}$ had higher intake of cakes (POR, 1.86; 95\% CI, 1.26-2.74), soft drinks (POR, 2.01; 95\% CI, 1.37-2.94), chocolate (POR, 1.84; 95\% CI, 1.26-2.69), chocolate snacks (POR, 2.07; 95\% CI, 1.42-3.03), and sweets (POR, 1.70; 95\% CI, 1.16-2.49), and lower intake of vegetables (POR, 0.92; 95\% CI, 0.42-0.90). Boys who reported watching more than $120 \mathrm{~min} / \mathrm{d}$ were more likely to consume sweets (POR, 1.91; 95\% CI, 1.27-2.88), hamburgers (POR, 1.72; 95\% CI, 1.13-2.61), and salty snacks (POR, 1.73; 95\% CI, $1.07-2.80$ ), and were less likely to consume fruit (POR, $0.68 ; 95 \%$ CI, 0.45-1.01) (Table 2).

Intakes of total energy and nutrients according to categories of time watching TV are shown in Table 3 for girls and Table 4 for 
Table 1

Description of participants' characteristics, according to categories of time spent watching TV, by sex*

\begin{tabular}{|c|c|c|c|c|}
\hline \multirow[t]{2}{*}{ Girls } & $\leq 60 \mathrm{~min}$ & $61-120 \mathrm{~min}$ & $>120 \mathrm{~min}$ & \multirow[t]{2}{*}{$P$-value } \\
\hline & $125(16.3)$ & $242(31.6)$ & $398(52.0)$ & \\
\hline \multicolumn{5}{|l|}{ Type of school } \\
\hline Public & $67(53.6)$ & $160(66.1)$ & $314(78.9)$ & \multirow[t]{2}{*}{$<0.001$} \\
\hline Private & $58(46.5)$ & $82(33.9)$ & $84(21.1)$ & \\
\hline Parents' education (y) & $12.6(4.34)$ & $11.2(4.55)$ & $9.8(4.36)$ & $<0.001$ \\
\hline \multicolumn{5}{|l|}{ BMI $\left(\mathrm{kg} / \mathrm{m}^{2}\right)^{\dagger}$} \\
\hline$<85$ th & $94(79.7)$ & $192(80.3)$ & $270(71.2)$ & \multirow[t]{3}{*}{0.059} \\
\hline$\geq 85$ th $\&<95$ th & $16(13.6)$ & $25(10.5)$ & $67(17.7)$ & \\
\hline$\geq 95$ th & $8(6.8)$ & $22(9.2)$ & $42(11.1)$ & \\
\hline \multicolumn{5}{|l|}{ Sports outside school } \\
\hline Never & $53(46.9)$ & $118(50.0)$ & $253(59.7)$ & \multirow[t]{3}{*}{$<0.001$} \\
\hline$\leq 1 \mathrm{~d} / \mathrm{wk}$ & $19(16.8)$ & $38(16.1)$ & $51(13.5)$ & \\
\hline $2 \mathrm{~d} / \mathrm{wk}$ to every day & $41(36.3)$ & 80 (33.9) & 74 (19.6) & \\
\hline \multicolumn{5}{|c|}{ Sports to the point of being breathless } \\
\hline Never & $41(36.3)$ & $93(39.9)$ & $188(50.5)$ & \multirow[t]{3}{*}{0.005} \\
\hline$\leq 1 \mathrm{~d} / \mathrm{wk}$ & $50(44.2)$ & $112(48.1)$ & $148(39.8)$ & \\
\hline $2 \mathrm{~d} / \mathrm{wk}$ to every day & $22(19.5)$ & $28(12.0)$ & $36(9.7)$ & \\
\hline Boys & $121(18.0)$ & $205(30.6)$ & $345(51.4)$ & \\
\hline \multicolumn{5}{|l|}{ Type of school } \\
\hline Public & $72(59.5)$ & $142(69.3)$ & $285(82.6)$ & \multirow[t]{2}{*}{$<0.001$} \\
\hline Private & $49(40.5)$ & $63(30.7)$ & $60(17.4)$ & \\
\hline Parents' education (y) & $14.0(4.12)$ & $11.7(4.26)$ & $10.1(4.37)$ & $<0.001$ \\
\hline \multicolumn{5}{|l|}{ BMI $\left(\mathrm{kg} / \mathrm{m}^{2}\right)^{\dagger}$} \\
\hline$<85$ th & $75(66.4)$ & $141(71.6)$ & $238(72.1)$ & \multirow[t]{3}{*}{0.731} \\
\hline$\geq 85$ th $\&<95$ th & $23(20.4)$ & $36(18.3)$ & $62(18.8)$ & \\
\hline$\geq 95$ th & $15(13.3)$ & $20(10.2)$ & $30(9.1)$ & \\
\hline \multicolumn{5}{|l|}{ Sports outside school } \\
\hline Never & $40(35.7)$ & $57(30.0)$ & $139(43.4)$ & \multirow[t]{3}{*}{0.037} \\
\hline$\leq 1 \mathrm{~d} / \mathrm{wk}$ & $18(16.1)$ & $29(15.3)$ & $47(14.7)$ & \\
\hline $2 \mathrm{~d} / \mathrm{wk}$ to every day & $54(48.2)$ & $104(54.7)$ & $134(41.9)$ & \\
\hline \multicolumn{5}{|c|}{ Sports to the point of being breathless } \\
\hline Never & $18(16.1)$ & $46(24.0)$ & $74(23.5)$ & \multirow[t]{3}{*}{0.211} \\
\hline$\leq 1 \mathrm{~d} / \mathrm{wk}$ & $54(48.2)$ & $99(51.6)$ & $151(47.9)$ & \\
\hline $2 \mathrm{~d} / \mathrm{wk}$ to every day & $40(35.7)$ & $47(24.5)$ & $90(28.6)$ & \\
\hline
\end{tabular}

BMI, body mass index

* Values are numbers (\%), except for parents' education presented as mean (SD).

According to the age- and sex-specific BMI references percentiles developed by the U.S. Centers for Disease Control and Prevention.

boys. In both sexes, adolescents who watched TV more than $120 \mathrm{~min} / \mathrm{d}$ reported a significantly higher intake of total fat, saturated fat, polyunsaturated fats (PUFAs), and cholesterol, and a lower intake of fiber, vitamin $\mathrm{C}$, magnesium, and potassium. Additionally, girls reported significantly lower intakes of proteins, complex carbohydrates, total vitamin A, folate, calcium, iron, and phosphorus.

Considering nutrient intake, spending more than $120 \mathrm{~min} / \mathrm{d}$ watching TV was significantly associated with higher intake of total fats and PUFAs and was associated with lower intake of magnesium, in both boys and girls (Tables 5 and 6). Additionally, girls who spent more than $120 \mathrm{~min} / \mathrm{d}$ watching TV had a lower intake of complex carbohydrates, fiber, total vitamin $\mathrm{A}$, folate, vitamin $C$, calcium, iron, phosphorus, and potassium (Table 5). Boys who spent more time watching TV had a higher intake of saturated fats and cholesterol (Table 6).

\section{Discussion}

The results of this study show that adolescents who watch TV more than $120 \mathrm{~min} / \mathrm{d}$ are more likely to consume high-fat and high-sugar foods and less fruits and vegetables. These results on food intake are consistent with previous studies that showed higher consumption of fast-foods, soft drinks, and snacks
Table 2

Associations between time spent watching TV and quartiles/tertiles of food intake, by sex

\begin{tabular}{|c|c|c|}
\hline \multirow[t]{2}{*}{ Girls } & $61-120 \mathrm{~min}$ & $>120 \mathrm{~min}$ \\
\hline & \multicolumn{2}{|l|}{ POR $(95 \% \mathrm{CI})^{*}$} \\
\hline Cakes & $1.26(0.84-1.90)$ & $1.86(1.26-2.74)$ \\
\hline Cookies & $0.96(0.64-1.44)$ & $1.09(0.74-1.59)$ \\
\hline Soft drinks & $1.98(1.32-2.95)$ & $2.01(1.37-2.94)$ \\
\hline Chocolates & $1.68(1.13-2.49)$ & $1.84(1.26-2.69)$ \\
\hline Chocolate snacks & $1.40(0.94-2.08)$ & $2.07(1.42-3.03)$ \\
\hline Sweets & $1.46(0.98-2.18)$ & $1.70(1.16-2.49)$ \\
\hline Hamburger & $0.95(0.63-1.43)$ & $1.38(0.93-2.04)$ \\
\hline Pizza & $0.98(0.65-1.50)$ & $1.09(0.74-1.63)$ \\
\hline Salty snacks & $1.21(0.76-1.92)$ & $1.17(0.75-1.82)$ \\
\hline Fruit & $0.72(0.48-1.08)$ & $0.79(0.54-1.17)$ \\
\hline Vegetables & $0.64(0.43-0.95)$ & $0.92(0.42-0.90)$ \\
\hline Boys & \multicolumn{2}{|l|}{ POR $(95 \% \mathrm{CI})^{*}$} \\
\hline Cakes & $0.78(0.51-1.19)$ & $1.20(0.80-1.79)$ \\
\hline Cookies & $0.86(0.57-1.31)$ & $0.96(0.64-1.43)$ \\
\hline Soft drinks & $0.98(0.65-1.48)$ & $1.24(0.83-1.85)$ \\
\hline Chocolates & $0.97(0.64-1.48)$ & $0.88(0.59-1.32)$ \\
\hline Chocolate snacks & $1.01(0.67-1.53)$ & $0.91(0.61-1.36)$ \\
\hline Sweets & $1.69(1.11-2.60)$ & $1.91(1.27-2.88)$ \\
\hline Hamburger & $1.40(0.90-2.15)$ & $1.72(1.13-2.61)$ \\
\hline Pizza & $1.40(0.89-2.19)$ & $1.03(0.67-1.58)$ \\
\hline Salty snacks & $1.55(0.94-2.56)$ & $1.73(1.07-2.80)$ \\
\hline Fruit & $0.86(0.57-1.31)$ & $0.68(0.45-1.01)$ \\
\hline Vegetables & $1.36(0.90-2.06)$ & $0.10(0.74-1.63)$ \\
\hline
\end{tabular}

$\mathrm{CI}$, confidence interval; POR, proportional odds ratio

POR to measure the odds of changing the category of intake, by food item, adjusted for parents' education and total energy intake, and using the category $\leq 60 \mathrm{~min}$, as reference.

[12-20] and lower consumption of fruit and vegetable [12,13, 16-19,21] according to time spent watching TV. Considering nutrient intake, more time watching TV was significantly associated with higher intake of total fats and PUFAs and with lower intake of minerals and vitamins. This finding is in accordance with data from a previous study [12] that found a significantly higher energy intake from fat among adolescents in the high TV/video category than the average and lower users. Another study [10] found significantly higher consumption of total fat among children who watch TV more than 2 h/d. However, our results differ from those reported in a study that found no clear pattern of differences in the intakes of fat, carbohydrates, proteins, vitamin $\mathrm{A}$, and magnesium, and higher calcium intake [11]. Nevertheless, these results should be interpreted cautiously as the sample size was limited and may have adversely affected the power of the study.

Most previous studies in children and adolescents were focused on the role of TV viewing on energy intake, as well as BMI [9-12]. Our work, showing an effect on mineral and vitamin intakes, supports that time watching TV may have other effects beyond that on BMI.

During the period of adolescence there is an increased demand for nutrients, and an inadequate intake of nutrients during adolescence can have long-term health implications [26, 27]. The American Heart Association recommends limiting consumption of fats, especially saturated fats, and an adequate intake of fruits and vegetables, combined with an active lifestyle in order to reduce the risk for cardiovascular disease [37]. Thus, based on our data it is expectable that more time watching TV may contribute to a favorable environment for the development of atherosclerosis and an increased risk for cardiovascular diseases throughout life.

Adolescents spending more time watching TV present a lower intake of calcium, which combined with lower amounts of 
Table 3

Median total energy and nutrient intake, according to categories of time spent watching TV, in girls

\begin{tabular}{|c|c|c|c|c|}
\hline \multirow[t]{2}{*}{ Girls } & $\leq 60 \mathrm{~min}$ & \multirow[t]{2}{*}{$61-120 \mathrm{~min}$} & \multirow[t]{2}{*}{$>120$ min } & \multirow[t]{2}{*}{$P$-value ${ }^{*}$} \\
\hline & Median (25th-75th percentiles) & & & \\
\hline Energy (kcal) & $2263(1865-2805)$ & 2359 (1936-2839) & $2361(1891-2897)$ & 0.470 \\
\hline Proteins (g/100 kcal) & $18.0(16.1-19.3)$ & $17.1(15.5-18.8)$ & $16.8(15.4-18.9)$ & 0.004 \\
\hline Total fat $(\mathrm{g} / 100 \mathrm{Kcal})$ & $31.2(28.8-35.7)$ & $31.6(28.4-33.9)$ & $32.5(30.0-35.4)$ & $<0.001$ \\
\hline Saturated fat $(\mathrm{g} / 100 \mathrm{Kcal})$ & $10.7(9.4-11.9)$ & $10.7(9.6-11.9)$ & $11.0(10.0-12.1)$ & 0.006 \\
\hline Monounsaturated fat (g/100Kcal) & $13.2(11.5-14.6)$ & $12.7(11.1-14.0)$ & $13.1(11.7-14.6)$ & 0.008 \\
\hline Polyunsaturated fat (g/100Kcal) & $5.0(4.3-5.7)$ & $4.9(4.4-5.6)$ & $5.3(4.6-6.1)$ & $<0.001^{*}$ \\
\hline Cholesterol (mg/100Kcal) & $126.8(108.7-150.7)$ & $127.4(106.4-148.7)$ & $134.7(113.8-155.9)$ & $0.044^{*}$ \\
\hline Carbohydrate (g/100Kcal) & $52.1(49.9-56.3)$ & $52.8(50.2-57.1)$ & $52.0(48.3-55.4)$ & 0.004 \\
\hline Complex Carbohydrate (g/100Kcal) & $16.5(14.1-18.9)$ & $16.2(12.5-18.7)$ & $15.4(13.4-17.5)$ & $<0.001$ \\
\hline Fibre $(\mathrm{g} / 100 \mathrm{Kcal})$ & $1.11(0.94-1.27)$ & $1.02(0.87-1.17)$ & $0.96(0.79-1.15)$ & $<0.001$ \\
\hline Total vitamin $\mathbf{A}(\mathrm{RE} / 100 \mathrm{Kcal})$ & $97.4(63.7-134.2)$ & $86.3(63.0-122.2)$ & $79.5(56.8-112.2)$ & $0.008^{*}$ \\
\hline Vitamin D (mcg/100Kcal) & $0.16(0.13-0.22)$ & $0.17(0.13-0.23)$ & $0.16(0.12-0.16)$ & $0.269^{*}$ \\
\hline Vitamin E (mg/100Kcal) & $0.37(0.34-0.46)$ & $0.36(0.30-0.41)$ & $0.36(0.30-0.42)$ & $0.015^{*}$ \\
\hline Folate $(\mathrm{mcg} / 100 \mathrm{Kcal})$ & $17.6(14.6-21.2)$ & $16.4(13.5-19.8)$ & $15.4(12.9-19.0)$ & $<0.001^{*}$ \\
\hline Vitamin C (mg/100Kcal) & $7.3(5.5-9.4)$ & $6.5(4.7-8.2)$ & $5.9(4.4-8.1)$ & $0.001^{*}$ \\
\hline Calcium (mg/100Kcal) & $49.2(42.0-59.9)$ & $46.8(37.1-55.8)$ & $42.9(34.9-52.6)$ & 0.002 \\
\hline Iron $(\mathrm{mg} / 100 \mathrm{Kcal})$ & $0.77(0.69-0.87)$ & $0.75(0.66-0.88)$ & $0.73(0.61-0.82)$ & $<0.001$ \\
\hline Magnesium (mg/100Kcal) & $16.0(14.5-16.8)$ & $15.1(13.8-16.2)$ & $14.5(13.1-15.8)$ & $<0.001$ \\
\hline Phosphorus (mg/100Kcal) & $71.1(64.7-77.1)$ & $67.5(61.2-73.6)$ & $65.2(58.5-71.9)$ & 0.001 \\
\hline Potassium (mg/100Kcal) & $173.7(153.7-187.1)$ & $163.0(143.4-178.9)$ & $157.3(139.5-177.0)$ & $<0.001$ \\
\hline
\end{tabular}

* Comparison based on ANOVA test, except for polyunsaturated fat, cholesterol, vitamins A, D, E, C and folate, for which the Kruskal-Wallis test was used.

physical activity, may contribute to poorer bone health in the long term $[38,39]$.

One of the main difficulties in assessing the nutrient intake is the lack of tools to enable precise measurement of food consumption. In this study, dietary intake was evaluated using a FFQ previously validated in the Portuguese adult population $[31,32]$ and food items more frequently eaten by adolescents were added to ensure a more complete evaluation of the adolescents' diet. Moreover, adolescents also were encouraged to list in an open section, foods eaten at least weekly, which were not in the FFQ. In large-scale epidemiologic studies, this type of questionnaire has been the method most widely used for the assessment of food intake because it is considered one of the most simple, quick to administer and not very expensive [40]. However, one limitation is the absence of a database with
Portuguese food composition; therefore, it was necessary to use a database that includes the nutritional composition of foreign foods.

On the other hand, as the time watching TV was self-reported, it may have been underestimated, mostly by those spending more time watching TV (social desirability response bias), which might have attenuated the differences between groups.

As strengths of our study we can mention its sample size, enhancing that, at the time of participants enrollment, school education was compulsory in Portugal until $15 \mathrm{y}$ of age, so it was expected that all adolescents born in 1990 were attending school. Although these adolescents are from a specific region of the country, they are not expected to be different from other Portuguese adolescents, especially from those who also reside in urban areas. However, some of the adolescents were not

Table 4

Median total energy and nutrient intake, according to categories of time watching TV, in boys

\begin{tabular}{|c|c|c|c|c|}
\hline \multirow[t]{2}{*}{ Boys } & $\leq 60 \min$ & \multirow[t]{2}{*}{$61-120 \mathrm{~min}$} & \multirow[t]{2}{*}{$>120 \mathrm{~min}$} & \multirow[t]{2}{*}{$P$-value ${ }^{*}$} \\
\hline & Median (25th-75th percentiles) & & & \\
\hline Energy (kcal) & $2450(1999-3028)$ & 2403 (2034-2857) & 2418 (1959-3037) & 0.668 \\
\hline Proteins (g/100 kcal) & $17.3(16.1-19.1)$ & $17.4(15.6-19.5)$ & $17.2(15.5-18.9)$ & 0.137 \\
\hline Total fat $(\mathrm{g} / 100 \mathrm{kcal})$ & $31.2(28.5-33.5)$ & $32.3(29.5-35.5)$ & $32.4(30.0-34.7)$ & 0.006 \\
\hline Saturated fat $(\mathrm{g} / 100 \mathrm{kcal})$ & $10.1(9.2-11.7)$ & $10.8(9.9-12.2)$ & $11.0(10.0-12.1)$ & 0.001 \\
\hline Monounsaturated fat (g/100 kcal) & $12.8(11.7-14.3)$ & $13.2(11.6-14.7)$ & $12.9(11.6-14.2)$ & 0.203 \\
\hline PUFA (g/100 kcal) & $4.6(4.2-5.3)$ & $5.0(4.5-5.7)$ & $5.3(4.6-6.1)$ & $<0.001^{*}$ \\
\hline Cholesterol (mg/100 kcal) & $124.1(108.2-144.0)$ & $131.1(113.5-153.3)$ & $134.5(111.8-157.7)$ & $0.024^{*}$ \\
\hline Carbohydrate (g/100 kcal) & $53.2(49.1-56.1)$ & $51.7(47.7-55.6)$ & $52.0(48.4-55.2)$ & 0.064 \\
\hline Complex carbohydrate (g/100 kcal) & $16.3(14.6-18.5)$ & $16.1(13.9-18.5)$ & $16.2(14.1-17.9)$ & 0.125 \\
\hline Fiber $(\mathrm{g} / 100 \mathrm{kcal})$ & $1.03(0.85-1.20)$ & $0.97(0.81-1.16)$ & $0.93(0.80-1.08)$ & $<0.001$ \\
\hline Total vitamin $\mathbf{A}(\mathrm{RE} / 100 \mathrm{kcal})$ & $84.0(58.9-118.3)$ & $84.9(61.5-118.3)$ & $81.2(60.3-111.9)$ & $0.647^{*}$ \\
\hline Vitamin D (mcg/100 kcal) & $0.15(0.12-0.23)$ & $0.17(0.13-0.22)$ & $0.18(0.13-0.23)$ & $0.266^{*}$ \\
\hline Vitamin E (mg/100 kcal) & $0.36(0.31-0.41)$ & $0.36(0.31-0.41)$ & $0.34(0.29-0.41)$ & $0.058^{*}$ \\
\hline Folate $(\mathrm{mcg} / 100 \mathrm{kcal})$ & $16.0(13.4-21.1)$ & $16.6(13.2-20.2)$ & $15.9(13.0-19.3)$ & $0.317^{*}$ \\
\hline Vitamin C (mg/100 kcal) & $6.5(4.6-8.6)$ & $5.8(4.4-7.8)$ & $5.5(4.0-7.2)$ & $0.006^{*}$ \\
\hline Calcium (mg/100 kcal) & $46.4(37.9-55.4)$ & $44.6(38.3-54.2)$ & $44.4(36.0-54.4)$ & 0.323 \\
\hline Iron $(\mathrm{mg} / 100 \mathrm{kcal})$ & $0.75(0.66-0.90)$ & $0.75(0.65-0.85)$ & $0.74(0.63-0.84)$ & 0.105 \\
\hline Magnesium (mg/100 kcal) & $15.2(14.0-16.8)$ & $14.8(13.4-16.0)$ & $14.7(13.1-15.5)$ & $<0.001$ \\
\hline Phosphorus (mg/100 kcal) & $68.4(62.7-75.0)$ & $67.9(61.3-73.9)$ & $66.3(60.3-73.8)$ & 0.180 \\
\hline Potassium (mg/100 kcal) & $163.6(147.8-185.6)$ & $158.4(141.6-178.4)$ & $154.4(138.3-171.2)$ & $<0.001$ \\
\hline
\end{tabular}

ANOVA, analysis of variance; PUFA, polyunsaturated fat; RE, resting energy

* Comparison based on ANOVA test, except for polyunsaturated fat, cholesterol, vitamins A, D, E, C and folate, for which the Kruskal-Wallis test was used. 
Table 5

Associations between time spent watching TV and quartiles of nutrient and vitamin intake, in girls

\begin{tabular}{lll}
\hline Girls & $61-120 \mathrm{~min}$ & $>120 \mathrm{~min}$ \\
\cline { 2 - 3 } & POR $(95 \% \mathrm{CI})^{*}$ & \\
\hline Proteins & $0.70(0.44-1.11)$ & $0.75(0.49-1.16)$ \\
Total fat & $0.92(0.56-1.49)$ & $1.60(1.01-2.54)$ \\
Saturated fat & $0.91(0.57-1.47)$ & $1.49(0.95-2.33)$ \\
Monounsaturated fat & $0.78(0.49-1.24)$ & $1.43(0.92-2.21)$ \\
PUFA & $0.97(0.62-1.51)$ & $1.75(1.15-2.67)$ \\
Cholesterol & $0.98(0.64-1.50)$ & $1.35(0.91-2.02)$ \\
Carbohydrate & $1.40(0.83-2.37)$ & $0.83(0.51-1.36)$ \\
Complex carbohydrate & $0.81(0.52-1.26)$ & $0.63(0.41-0.96)$ \\
Fiber & $0.62(0.40-0.96)$ & $0.41(0.27-0.62)$ \\
Total vitamin A & $0.79(0.53-1.19)$ & $0.65(0.46-0.96)$ \\
Vitamin D & $1,00(0.67-1.49)$ & $0.89(0.61-1.30)$ \\
Vitamin E & $0.73(0.47-1.13)$ & $0.83(0.55-1.26)$ \\
Folate & $0.60(0.39-0.92)$ & $0.49(0.32-0.73)$ \\
Vitamin C & $0.64(0.42-0.96)$ & $0.59(0.40-0.87)$ \\
Calcium & $0.66(0.43-1.01)$ & $0.45(0.30-0.68)$ \\
Iron & $0.69(0.44-1.08)$ & $0.53(0.35-0.82)$ \\
Magnesium & $0.71(0.44-1.16)$ & $0.50(0.31-0.79)$ \\
Phosphorus & $0.64(0.40-1.02)$ & $0.55(0.35-0.85)$ \\
Potassium & $0.56(0.35-0.89)$ & $0.44(0.28-0.68)$ \\
\hline Clam & &
\end{tabular}

$\mathrm{CI}$, confidence interval; POR, proportional odds ratio; PUFA, polyunsaturated fat * POR to measure the odds of changing the category of intake, by food item, adjusted for parents' education and total energy intake, and using the category $\leq 60 \mathrm{~min}$, as reference.

included in this analysis. These losses could bias our sample because there was a significantly higher percentage of males among those who were excluded, with less-educated parents and mostly from public schools. Once our analysis was stratified by sex, no effect is expected on the association found in each sex. However, as our results showed that adolescents with lesseducated parents and from public schools spend more time watching TV, the exclusion of some adolescents presenting these characteristics probably led to an underestimation of the time spent in this activity.

\section{Table 6}

Associations between time spent watching TV and quartiles of nutrient and vitamin intake, in boys

\begin{tabular}{lll}
\hline Boys & \multicolumn{1}{l}{$61-120 \mathrm{~min}$} & $>120 \mathrm{~min}$ \\
\cline { 2 - 3 } & POR $(95 \% \mathrm{CI})^{*}$ & \\
\hline Proteins & $1.10(0.68-1.79)$ & $0.80(0.50-1.28)$ \\
Total fat & $1.53(0.91-2.55)$ & $1.71(1.03-2.83)$ \\
Saturated fat & $1.92(1.18-3.14)$ & $2.08(1.29-3.36)$ \\
Monounsaturated fat & $1.45(0.89-2.36)$ & $1.19(0.74-1.91)$ \\
PUFA & $1.53(0.95-2.46)$ & $2.05(1.29-3.25)$ \\
Cholesterol & $1.40(0.89-2.18)$ & $1.73(1.13-2.67)$ \\
Carbohydrate & $0.57(0.33-0.98)$ & $0.59(0.35-1.02)$ \\
Complex carbohydrate & $0.87(0.55-1.39)$ & $0.71(0.45-1.11)$ \\
Fiber & $0.88(0.56-1.38)$ & $0.67(0.43-1.05)$ \\
Total vitamin A & $1.17(0.77-1.78)$ & $1.00(0.67-1.49)$ \\
Vitamin D & $1.15(0.75-1.76)$ & $1.40(0.93-2.11)$ \\
Vitamin E & $1.32(0.84-2.08)$ & $0.93(0.60-1.43)$ \\
Folate & $1.13(0.73-1.75)$ & $0.97(0.64-1.48)$ \\
Vitamin C & $0.86(0.56-1.32)$ & $0.66(0.44-1.00)$ \\
Calcium & $1.11(0.71-1.72)$ & $1.08(0.71-1.64)$ \\
Iron & $1.24(0.78-1.97)$ & $0.90(0.57-1.41)$ \\
Magnesium & $0.90(0.54-1.51)$ & $0.60(0.36-0.98)$ \\
Phosphorus & $0.89(0.55-1.46)$ & $0.80(0.50-1.29)$ \\
Potassium & $0.88(0.55-1.42)$ & $0.74(0.47-1.18)$ \\
\hline
\end{tabular}

$\mathrm{CI}$, confidence interval; POR, proportional odds ratio; PUFA, polyunsaturated fat * POR to measure the odds of changing the category of intake, by food item, adjusted for parents' education and total energy intake, and using the category $\leq 60 \mathrm{~min}$, as reference.

\section{Conclusions}

Our results are in accordance with previous evidence but add information about the effect of TV viewing on nutrient intake. Our findings suggest that the effect of time spent watching television on dietary intake is not limited to obesity and higher consumption of unhealthy foods, but also has implications on the intake of vitamins and minerals. So our results support that more time watching TV may contribute to an unfavorable environment and consequently may have long-term health implications.

\section{Acknowledgments}

The study was supported by grants from the Portuguese Foundation for Science and Technology: POCTI/SAU-ESP/62399/ 2004, FCOMP-01-0124-FEDER-015750 (Ref. FCT PTDC/SAU-EPI/ $115254 / 2009$ ), and SFRH/BD/78153/2011 to JA.

\section{References}

[1] Daniels SR, Arnett DK, Eckel RH, Gidding SS, Hayman LL, Kumanyika S, et al. Overweight in children and adolescents: pathophysiology, consequences, prevention, and treatment. Circulation 2005;111:1999-2012.

[2] James PT, Leach R, Kalamara E, Shayeghi M. The worldwide obesity epidemic. Obes Res 2001;9(Suppl 4):228S-33S.

[3] Marshall SJ, Biddle SJ, Gorely T, Cameron N, Murdey I. Relationships between media use, body fatness and physical activity in children and youth: a meta-analysis. Int J Obes Relat Metab Disord 2004;28:1238-46.

[4] Rey-Lopez JP, Ruiz JR, Vicente-Rodriguez G, Gracia-Marco L, Manios Y, Sjostrom M, et al. Physical activity does not attenuate the obesity risk of TV viewing in youth. Pediatr Obes 2012;7:240-50.

[5] Tremblay MS, LeBlanc AG, Kho ME, Saunders TJ, Larouche R, Colley RC, et al. Systematic review of sedentary behaviour and health indicators in schoolaged children and youth. Int J Behav Nutr Phys Act 2011;8:98.

[6] Hancox RJ, Milne BJ, Poulton R. Association between child and adolescent television viewing and adult health: a longitudinal birth cohort study. Lancet 2004;364:257-62.

[7] Mamun AA, O'Callaghan MJ, Williams G, Najman JM. Television watching from adolescence to adulthood and its association with BMI, waist circumference, waist-to-hip ratio and obesity: a longitudinal study. Public Health Nutr 2012;12:1-11.

[8] Robinson TN. Reducing children's television viewing to prevent obesity: a randomized controlled trial. JAMA 1999;282:1561-7.

[9] Crespo CJ, Smit E, Troiano RP, Bartlett SJ, Macera CA, Andersen RE. Television watching, energy intake, and obesity in US children: results from the third National Health and Nutrition Examination Survey, 1988-1994. Arch Pediatr Adolesce Med 2001;155:360-5.

[10] Manios Y, Kondaki K, Kourlaba G, Grammatikaki E, Birbilis M, Ioannou E. Television viewing and food habits in toddlers and preschoolers in Greece: the GENESIS study. Eur J Pediatr 2009;168:801-8.

[11] Proctor MH, Moore LL, Gao D, Cupples LA, Bradlee ML, Hood MY, et al Television viewing and change in body fat from preschool to early adolescence: the Framingham Children's Study. Int J Obes Relat Metab Disord 2003;27:827-33.

[12] Utter J, Neumark-Sztainer D, Jeffery R, Story M. Couch potatoes or french fries: are sedentary behaviors associated with body mass index, physical activity, and dietary behaviors among adolescents? J Am Diet Assoc 2003;103:1298-305.

[13] Barr-Anderson DJ, van den Berg P, Neumark-Sztainer D, Story M. Characteristics associated with older adolescents who have a television in their bedrooms. Pediatrics 2008;121:718-24.

[14] French SA, Story M, Neumark-Sztainer D, Fulkerson JA, Hannan P. Fast food restaurant use among adolescents: associations with nutrient intake, food choices and behavioral and psychosocial variables. Int J Obes Relat Metab Disord 2001;25:1823-33.

[15] Phillips SM, Bandini LG, Naumova EN, Cyr H, Colclough S, Dietz WH, et al. Energy-dense snack food intake in adolescence: longitudinal relationship to weight and fatness. Obes Res 2004;12:461-72.

[16] Salmon J, Campbell KJ, Crawford DA. Television viewing habits associated with obesity risk factors: a survey of Melbourne schoolchildren. Med J Aust 2006;184:64-7.

[17] Utter J, Scragg R, Schaaf D. Associations between television viewing and consumption of commonly advertised foods among New Zealand children and young adolescents. Public Health Nutr 2006;9:606-12.

[18] Vereecken CA, Todd J, Roberts C, Mulvihill C, Maes L. Television viewing behaviour and associations with food habits in different countries. Public Health Nutr 2006;9:244-50. 
[19] Pearson N, Ball K, Crawford D. Mediators of longitudinal associations between television viewing and eating behaviours in adolescents. Int J Behav Nutr Phys Act 2011;8:23.

[20] Rey-Lopez JP, Vicente-Rodriguez G, Repasy J, Mesana MI, Ruiz JR, Ortega FB, et al. Food and drink intake during television viewing in adolescents: the Healthy Lifestyle in Europe by Nutrition in Adolescence (HELENA) study. Public Health Nutr 2011;14:1563-9.

[21] Boynton-Jarrett R, Thomas TN, Peterson KE, Wiecha J, Sobol AM, Gortmaker SL. Impact of television viewing patterns on fruit and vegetable consumption among adolescents. Pediatrics 2003;112(6 Pt 1):1321-6.

[22] World Health Organization. Young people's health-a challenge for society Report of a Study Group on Young People and Health for All by the Year 2000. Geneva: World Health Organization; 1986.

[23] Shepherd R, Dennison CM. Influences on adolescent food choice. Proc Nutr Soc 1996;55:345-57.

[24] Thomas J. Food choices and preferences of schoolchildren. Proc Nutr Soc 1991;50:49-57.

[25] World Health Organization. Nutrition in adolescence-Issues and challenges for the health sector. Issues in adolescent health and development. Geneva: World Health Organization; 2005.

[26] Spear BA. Adolescent growth and development. J Am Diet Assoc 2002;102(Suppl):S23-9.

[27] Stang J, Story MT, Harnack L, Neumark-Sztainer D. Relationships between vitamin and mineral supplement use, dietary intake, and dietary adequacy among adolescents. J Am Diet Assoc 2000;100:905-10.

[28] American Academy of Pediatrics: Children, adolescents, and television. Pediatrics 2001;107:423-6.

[29] Inequalities in young people's health. Health Behaviour in School-aged Children (HBSC) study: international report from the 2005/2006 survey. Copenhagen: WHO Regional Office for Europe; 2008.
[30] Ramos E, Barros H. Family and school determinants of overweight in 13-year-old Portuguese adolescents. Acta paediatr 2007;96:281-6.

[31] Lopes C. Dietary factors and myocardial infarction: a community-based case-control study [PhD]. Porto: University of Porto; 2000.

[32] Lopes C, Aro A, Azevedo A, Ramos E, Barros H. Intake and adipose tissue composition of fatty acids and risk of myocardial infarction in a male Portuguese community sample. J Am Diet Assoc 2007;107:276-86.

[33] Amaral T, Nogueira C, Paiva I, Lopes C, Cabral S, Fernandes P, et al. Weights and food portions [in Portuguese]. Rev Port Nutr 1993;2:13-23.

[34] Lopes C, Fernandes PV, Barros H. Food frequency questionnaire-the effect of the food list extension on participants' classification. Arq Med 1994;8:291-4.

[35] Silva D, Rego C, Guerra A, Sinde S, Zara L, Moreira P. Characterization of food habits and comparative study between two methods of food assessment in adolescents [in Portuguese]. Rev Aliment Hum 2004;10:33-40.

[36] Kuczmarski RJ, Ogden CL, Guo SS, Grummer-Strawn LM, Flegal KM, Mei Z, et al. 2000 CDC Growth Charts for the United States: methods and development. Vital and health statistics Series 11. Data from the national health survey; 2002:1-190.

[37] Kavey RE, Daniels SR, Lauer RM, Atkins DL, Hayman LL, Taubert K. American Heart Association guidelines for primary prevention of atherosclerotic cardiovascular disease beginning in childhood. J Pediatr 2003;142:368-72.

[38] Bailey DA, Martin AD, McKay HA, Whiting S, Mirwald R. Calcium accretion in girls and boys during puberty: a longitudinal analysis. J Bone Miner Res 2000;15:2245-50.

[39] Greer FR, Krebs NF. Optimizing bone health and calcium intakes of infants, children, and adolescents. Pediatrics 2006;117:578-85.

[40] Willett W. Food-frequency methods. In: Willett W, editor. Nutritional epidemiology. 2nd ed. New York: Oxford University Press; 1998. p. 74-100. 